\title{
Small but mighty: a functional look at bacterial sHSPs
}

\author{
Igor Obuchowski ${ }^{1} \cdot$ Krzysztof Liberek $^{1}$
}

Accepted: 12 March 2020 / Published online: 16 April 2020

(C) The Author(s) 2020

\begin{abstract}
Small heat shock proteins (sHSPs) are widespread in every kingdom of life, being indispensable for protein quality control networks. Alongside canonical chaperone functions, sHSPs seem to have been a very plastic scaffold for acquiring multiple related functions across evolution. This review aims to summarize what is known about sHSPs functioning in the Bacteria Kingdom.
\end{abstract}

Keywords Small HSPs $\cdot$ Bacteria $\cdot$ Proteostasis $\cdot$ Chaperone $\cdot$ Aggregation

\section{From discovery to common features}

The first discovered member of the small heat shock protein family was $\alpha$-crystallin, which has been known for more than a century to be the major structural protein of the vertebrate eye lens (Mörner 1894). Many years later, a well-established family of $\alpha$-crystallins was found to be related to Drosophila melanogaster small heat shock proteins (abbreviated as sHSPs), which justified including them in a common classification group of sHSPs (Ingolia and Craig 1982). This, together with the heat shock response-focused research boom of these years, has led to broad investigations on small heat shock proteins.

Although sHSPs sequence conservation is rather limited, especially in contrast to other heat shock proteins, they started to be identified by homology to $\alpha$-crystallins and the fruit fly sHSPs (Key et al. 1981; Russnak et al. 1983; Booth et al. 1988; Nerland et al. 1988; Verbon et al. 1992; Lee et al. 1992). As the number of identified sHSPs has been growing, their polypeptides were found to be typically subdivided into an $\alpha$-crystallin domain, the most homologous region in their sequence and a much less conserved flanking $\mathrm{N}$ - and $\mathrm{C}$ termini (Van Montfort et al. 2001). At the same time, multiple sHSPs were shown to form large dynamic complexes (Arrigo

Igor Obuchowski

igor.obuchowski@gmail.com

1 Intercollegiate Faculty of Biotechnology UG-MUG, University of Gdansk, Abrahama 58, 80-307 Gdansk, Poland and Welch 1987; Behlke et al. 1991) and, later, their dissociation to be regulated by temperature changes ( $\mathrm{Fu}$ and Chang 2004). Accompanying structural studies has shown that sHSPs are especially rich in $\beta$-structures ( $\mathrm{Li}$ and Spector 1974; Merck et al. 1993), finally leading to the first resolved bacterial sHSP structure (Kim et al. 1998a, b). It was later found that the $\beta$-sandwich fold is a common, highly conserved feature of all sHSPs.

In addition to structural studies, a great deal of effort was put into determining the functional traits of sHSPs. Initial studies on $\alpha$-crystallins focused on the medical contexts, especially prevention of cataract formation (Roy and Spector 1976) and later on roles in tumor cell growth (Gaestel et al. 1989) and cell differentiation (Stahl et al. 1992). Concerning the presence of sHSPs in organisms from every kingdom of life, it appeared challenging to elucidate their common functions (Schlesinger 1986) suggested by their striking fold conservation. sHSPs were often found to be highly overexpressed at heat stress - conferring thermotolerance to some organisms (Loomis and Wheeler 1982; Berger and Woodward 1983) but showing no feasible phenotype when disrupted in others (Susek and Lindquist 1989; Praekelt and Meacock 1990). It took detailed biochemical studies to demonstrate that sHSPs act as molecular chaperones both in animals (Jakob et al. 1993; Wang and Spector 1995), plants (Lee et al. 1995) and bacteria (Chang et al. 1996; Thomas and Baneyx 1998).

From the evolutionary point of view, small HSPs divergence across all kingdoms of life seems to have been driven with great plasticity towards acquiring different functions (De Jong et al. 1993; Carra et al. 2017). There is a clear tendency to increase the number of sHSP-coding genes with increasing organism 
complexity, which accompanies an increased diversity of performed functions. Bacteria, considered to be the least complex organisms, usually express only one or two sHSPs (Haslbeck et al. 2005) that can still perform several functions in the bacterial cell. To date, the most important reported bacterial sHSPs functions are (i) molecular chaperone function, which can be subdivided into two distinct modes of action, transient interactions with unfolding polypeptides at mild proteotoxic stress and high-affinity interactions observed at massive aggregation events; (ii) protection of cell membrane components and membrane integrity; and (iii) a handful of more specific functions dedicated to survival in adverse environments.

\section{Chaperone activity: stable interactions}

The best studied chaperone activity of sHSPs is preventing formation of large amorphous aggregates, which seems to be evolutionarily the oldest and most important sHSPs function for bacteria. To perform it, sHSPs intercept unfolding intermediates and co-assemble in so-called sHSPs-substrate assemblies that serve as the safe storage for polypeptides before refolding. This section will focus on formation, architecture, and refolding of substrates from sHSPs-substrate assemblies.

In 1996, after multiple evidence appeared of eukaryotic sHSPs being molecular chaperones (Jakob et al. 1993; Boyle and Takemoto 1994; Singh et al. 1995; Wang and Spector 1995; Raman et al. 1995), Hsp16.3 from Mycobacterium tuberculosis was shown to suppress citrate synthase (CS) thermal aggregation, although it could not protect CS activity nor refold it afterwards (Chang et al. 1996). The same year Escherichia coli IbpA \& IbpB, previously described as inclusion body associated proteins (Allen et al. 1992), were found to co-localize with the aggregated protein fraction in heat shock conditions (Laskowska et al. 1996). Later, they were also shown to confer thermotolerance and to stabilize aggregated proteins for further refolding (Thomas and Baneyx 1998; Veinger et al. 1998). These observations, taken together with sequence homology to eukaryotic sHSPs, gave a solid proof for considering bacterial sHSPs as molecular chaperones.

sHSPs chaperone activity is exerted by stabilization of structurally damaged proteins for subsequent refolding by the Hsp70-Hsp100 bi-chaperone system. It is achieved by sHSPs binding to partially unfolded polypeptides in stress conditions and by driving their aggregation towards characteristic complexes called sHSPs-substrate assemblies. sHSPs showing this activity are often called aggregases, which might be misleading as SHSP-substrate assemblies and the assembly process itself differ from amorphous aggregates and aggregation. To date, the direct molecular mechanism of the assembly formation process remains elusive except in several details. It is known that substrate binding, executed by the N-terminus and $\alpha$-crystalline domain (Fu et al. 2005; Tomoyasu et al.
2010; Fu et al. 2013b; Fu and Chang 2006), is preceded by sHSPs oligomers dissociation into smaller speciespreferably dimers (Fu and Chang 2004) - that are postulated to be the active species in this process. It is typically observed also for nonbacterial sHSPs (Haslbeck and Vierling 2015).

Efficient polypeptides sequestering in assemblies requires the presence of stoichiometric amounts of sHSPs - at least in vitro (Friedrich et al. 2004; Fu and Chang 2004; Jiao et al. 2005). In vivo sHSP genes are commonly found to undergo massive expression upregulation in stress conditions. It is more pronounced than upregulation of any other chaperone as judged by cellular protein content and transcription profiling (Richmond et al. 1999; Münchbach et al. 1999; Lee et al. 1998) - presumably providing enough sHSPs for efficient in vivo substrate sequestering. On the other hand, little is known of the substrates trapped by bacterial sHSPs. It can only be deduced from studies on yeast SHSPs, that these are stored in near-native conformation (Ungelenk et al. 2016), which is probably one of the factors facilitating further disaggregation and refolding. Speaking of assemblies architecture, substrate molecules are postulated to be held in the core of the assembly with only a limited number of sHSPs and shielded from the environment by the sHSPs outer shell (Żwirowski et al. 2017); however, there are no direct structural data on this subject.

The ability of sHSPs to stabilize unfolded polypeptides provoked obvious concerns about the later fate of trapped polypeptides. In 1998, Veigner and colleagues showed that E. coli IbpB, when present during malate dehydrogenase thermal aggregation, improves further disaggregation by dedicated chaperones (Veinger et al. 1998). This finding, which was also established for eukaryotic sHSPs (Lee et al. 1997), has led to the integration of sHSPs as a part of chaperone network. It became clear that bacterial (and other) sHSPs modulate protein aggregation in order to hold unfolded polypeptides in a refolding competent state (Matuszewska et al. 2005; Ratajczak et al. 2009). In 2017, Żwirowski et al. proposed the mechanism of extraction and refolding of misfolded polypeptides from sHSPs-substrate assemblies. They have shown that specifically Hsp70 chaperone binds to the assemblies to outcompete sHSPs, which allows for single polypeptides extraction by recruited Hsp100 disaggregase. The authors suggested a lack of direct interaction between Hsp70 and sHSPs being removed from assemblies - just affinity competition for unfolded polypeptides trapped in assemblies. Additionally, several experiments were performed with yeast proteins, suggesting a common described mechanism (Żwirowski et al. 2017).

To date, the majority of studies linking sHSPs action in protein aggregation and their interference with disaggregating chaperones were carried out in the E. coli system, where 2 sHSPs$\mathrm{IbpA}$ and $\mathrm{IbpB}$ - cooperate with each other. Interestingly, IbpA, when present during substrate aggregation, is enough to generate assemblies with the substrate but also inhibits its further 
disaggregation. This inhibition is lost in the presence of $\mathrm{IbpB}$ alongside IbpA. However, IbpB alone has a much less pronounced effect on disaggregation, being barely able to generate assemblies with unfolding substrate (Ratajczak et al. 2009; Matuszewska et al. 2005; Thomas and Baneyx 1998). Recently, IbpB activity was shown to interfere with IbpA canonical substrate binding, which results in easier sHSPs removal from assemblies and effective disaggregation (Obuchowski et al. 2019).

An alternative example of 2 sHSPs bacterial system comes from Deinococcus radiodurans, where sHSPs act separately. One of them, Hsp20.2, is very effective in assembly generation when in the presence of an aggregating substrate, and the other, Hsp17.7, is capable of sustaining substrate activity (or postponing activity loss) in otherwise denaturing conditions (Bepperling et al. 2012). This activity protection is achieved by transient interactions with the substrate, which will be discussed as a stand-alone phenomenon in the next section. Overall, both $E$. coli and $D$. radiodurans systems seem rather atypical as most bacteria express only one sHSP (Haslbeck et al. 2005). The best studied single sHSP is Hsp16.3 from M. tuberculosis that was used for functional studies showing typical assembly forming chaperone activity (Chang et al. 1996), surface hydrophobicity changes (Yang et al. 1999), and oligomers dissociation (Fu and Chang 2004) upon heat treatment. Intensive studies on Hsp16.3 have also revealed its non-chaperone functions that will be described in another section.

\section{Chaperone activity: transient interactions}

Another important, yet less studied, example of sHSPs chaperone activity is their ability to protect enzymes from inactivation or postpone their activity loss upon mild denaturing conditions. It is exerted via transient, cyclic interactions (in contrast to stable assembly generation-driving interactions) with hydrophobic regions of slightly damaged protein substrates, somehow directing them back to a native fold. This section will focus on several bacterial sHSPs that were shown to act in this mode of chaperone activity.

From the mechanistic point of view, it is highly elusive how bacterial sHSPs protect enzyme activity; however, it can be deduced from several studies on vertebrate sHSPs. These have been shown to weakly and transiently interact with misfolded intermediates - forming dynamic high molecular weight assemblies (Kulig and Ecroyd 2012). Target substrate hydrophobicity and stability largely determines if sHSPs would tightly interact with the substrate, stabilizing it for further refolding or transiently binding and release. As the misfolding intermediate is subsequently bound and released, it is secured from aggregation and can fold into the native structure (Kulig and Ecroyd 2012; Hatters et al. 2001).
In bacteria, an enzyme activity protection assay was initially applied for M. tuberculosis Hsp16.3. Although the assay showed chaperone activity towards citrate synthase as monitored by static light scattering, the authors could not observe any protection of citrate synthase activity (Chang et al. 1996). On the other hand, E. coli IbpA and IbpB turned out to be more successful in this type of experiment. Together, they were shown to protect luciferase from thermal inactivation (although weakly) (Matuszewska et al. 2005) and both separately and together - to protect several other enzymes from oxidative and freeze-thaw inactivation (Kitagawa et al. 2002). Interestingly, the authors claim IbpB to be more effective than IbpA in enzyme activity protection (Kitagawa et al. 2002), which is consistent with later reported in vivo IbpB ability to protect metabolic enzymes activities during heat stress (Fu et al. 2013a). In contrast, IbpA was shown to be much more potent than IbpB in forming stable assemblies with aggregating polypeptides. This suggests a diversity in their activities although they cooperate when acting as mixed complexes (Ratajczak et al. 2009; Matuszewska et al. 2005; Hochberg et al. 2018; Obuchowski et al. 2019). Finally, it seems that cooperation is not a key feature for this type of sHSPs activity. Here is an example from D. radiodurans, which Hsp17.7 was shown to effectively protect CS from thermal inactivation in contrast to its paralog Hsp20.2 that can neither protect CS activity nor cooperate with Hsp17.7 (Bepperling et al. 2012).

Leaving aside the cooperation issues, it seems that the ability to form assemblies with aggregating substrates and protect enzyme activity are somehow in opposition. This is supported by research on single sHSPs: M. tuberculosis Hsp16.3 that is only able to form assemblies (Chang et al. 1996) and - in contrastits close relative sHsp18 from Mycobacterium leprae, which effectively protects restriction enzymes from thermal inactivation, however was not assayed for generating stable complexes/ assemblies with aggregating substrate (Lini et al. 2008).

\section{Chaperone activity: conclusion}

Although sHSPs-dependent enzyme protection and sHSPssubstrate complex formation were already shown in the very first publication attributing sHSPs with chaperone activity (Jakob et al. 1993), these modes of action are rarely assayed when new bacterial sHSP appears. The most exploited assay in this field (and technically the easiest) is in vitro aggregation protection monitored via static light scattering. It does not directly indicate whether prevention of sample scattering increase is achieved by protecting a substrate's native fold or by scavenging unfolded polypeptides within soluble assemblies. Therefore, it does not allow discrimination of sHSPs chaperone activity modes. The same concern may apply to widely exploited experiments on in vivo aggregation, where the amount of cellular insoluble (aggregated) protein is compared between strains. Here again, one could ask if aggregates volume is lower due to 
sHSPs-dependent substrate activity (fold) maintenance or by providing a more potent substrate for effective disaggregation (sHSPs-substrate assemblies instead of amorphous aggregates).

From the "end user" point of view, however, it is the final outcome that matters, e.g., reduced aggregation/aggregates volume. Thus, we can see two different strategies to achieve that. It can only be speculated that the path of aggregation modification may be more effective in counteracting severe proteotoxic stress when unfolding events occur frequently and rapidly among a larger pool of polypeptides. In contrast, the activity protection path might be favorable under less severe conditions, when only a smaller pool of less stable substrates is exposed to the risk of unfolding.

Finally, there is an evidence for the third option. Klein and colleagues (Klein et al. 2001) have shown that IbpA, a single sHSP from the marine bacterium Vibrio harveyi, complexes in vivo with aggregated protein fraction similarly to most typical sHSPs. However, one of their experiments suggests that the aggregated protein fraction (containing IbpA) is highly stable during cell recovery. This in turn could suggest a dilution of IbpAdetoxified, stable aggregate species (IbpA-substrate assemblies?) by cell divisions as a mechanism of aggregates handling in $V$. harveyi; however, this would require further research to prove.

\section{Membrane-focused chaperone}

Among chaperone-focused research, accompanying localization studies have shown several bacterial sHSPs to locate in cell membranes (Lee et al. 1992; Laskowska et al. 1996; Otani et al. 2005). This feature was further exploited in several different bacteria species, giving rise to the concept of sHSPs as lipochaperones (Maitre et al. 2014). This section will attempt to summarize what is known about sHSPs-membranes relationship.

Starting from the work of Horvath and colleagues, who identified hsp17 as a "fluidity gene" in Synechocystis PCC 6803 (Horvath et al. 1998), it was shown that several sHSPs are capable of reducing membranes fluidity in permissive or heat stress conditions and in the presence of organic solvents (Torok et al. 2001; Capozzi et al. 2011). To perform this task, sHSPs associate with membranes not as higher-order oligomers, but rather in the form of dissociated species (Zhang et al. 2005; Maitre et al. 2012), which are also active substrate-binding forms concerning canonical chaperone activity. Subsequently, Maitre and colleagues proposed a combined model of chaperone and lipochaperone Oenococcus oeni Lo18 activities that summed up extensive studies in this field (Maitre et al. 2014). However, no further molecular details of Lo18 lipochaperone sHSPs activity are available.

Moving from general to more specific lipochaperone activity, an ability of cyanobacteria sHSPs to maintain thylakoid membrane integrity and their canonical chaperone activity towards phycocyanins (Nakamoto and Honma 2006) were integrated and analyzed in the context of resistance to UVBinduced damage (Balogi et al. 2008) and oxidative stress (Sakthivel et al. 2009) in Synechocystis. Presented data strongly highlight the importance of HspA, cyanobacterial sHSP, for preserving photosynthetic thylakoid functions - both through maintaining general thylakoid membrane integrity (lipochaperone) and by specific protection of phycobilisomes and PSII complexes from inactivation (dedicated chaperone).

\section{Chaperone for special tasks}

Small HSPs are featured with the least conserved sequences among all chaperone families, which allowed great evolutionary plasticity towards acquiring new functions. This is especially evident in multiple sHSPs-expressing organisms like plants or animals, where many sHSPs perform other than general chaperone functions. In bacteria, it is less evident (or less investigated), although there are several 'case studies' that demonstrate specific, dedicated chaperone-target interactions or other non-chaperone sHSP function. This section is an attempt to briefly summarize bacterial sHSPs activities that are separate from the already discussed canonical chaperone activities.

An example of specific sHSP function was found in Agrobacterium tumefaciens. HspL, one of the four sHSPs expressed in this bacterium, was found to be important for A. tumefaciens virulence towards plant cells, e.g., transferring its DNA into plant cells in order to take over plant metabolism. HspL, but no other A. tumefaciens sHSP, effectively protects VirB8 protein (Tsai et al. 2012) that is an essential assembly factor for type IV secretion system responsible for DNA injection into plant cells (Baron and Cellulaire 2006). VirB8 protein is conserved across evolution (Baron and Cellulaire 2006); therefore, a follow-up study, concerning the VirB8dependent mammal pathogen, appeared. Brucella suis, a facultative intracellular bacterial pathogen of mammals, also uses the IV secretion system for virulence particle delivery to the host cells. Unlike in A. tumefaciens, it was shown that $B$. suis IbpA is not required for virulence (Berta et al. 2014). The second B. suis sHSP (also annotated as IbpA) was not analyzed based on significantly lower homology to A. tumefaciens HspL (Berta et al. 2014). Considering these data, it seems that the relationship of VirB8 to HspL found in A. tumefaciens is rather limited to a narrow species group.

As sHSPs are responsible for protecting proteostasis on the molecular level, they may also play a more general role in some of the strategies for survival in a hostile environment. One of these strategies is a biofilm formation that is a three-dimensional, complex structure formed of bacteria settled in an extracellular matrix. Biofilms are more resistant to various stresses (antibiotics, heavy metal ions, oxidation) than free-living bacterial cells, enhancing their ability to survive (Flemming et al. 2016). In E. coli, it was shown that $\mathrm{IbpA}$ and $\mathrm{IbpB}$ indirectly influence 
biofilm formation, delaying its establishing when absent. In $\triangle i b p A B$ strains, cells are affected by endogenous oxidative stress, which results in overproduction of indole, that in turn inhibits formation of the biofilm (Kuczyńska-Wiśnik et al. 2010).

Another strategy for survival in adverse environments, where sHSPs may interfere, is cyst formation. In opposition to biofilm, a microbial cyst is a resting/dormant stage, dedicated to passively survive harsh conditions. Azotobacter vinelandii is a free-living soil bacterium whose sHSP, Hsp20, was shown to be essential for cyst desiccation resistance. Consistent with the function, hsp20 gene in A. vinelandii is under the control of RpoS sigma factor (Cocotl-Yañez et al. 2014) that governs expression of many genes crucial for bacterial survival in adverse environments. This is however atypical for sHSPs as most of them in related bacterial species are under the control of RpoH paralogs - master regulators of the heat shock response in these species (Tilly et al. 1986).

The most complete story in terms of sHSPs-affected survival in adverse environments comes from M. tuberculosis. Its Hsp16.3 sHSP is associated with dormancy and stationary phase, where it was shown to be expressed the most. Hsp16.3 expression results in lower cell susceptibility to autolysis at the cost of slower growth rate (Yuan et al. 1996). Hsp16.3 was also shown to be instrumental in cell wall thickening that provides additional protection during dormancy (Cunningham and Spreadbury 1998). Similarly to the growth on media, research conducted in pathogen-host systems has also shown that Hsp16.3 plays a role in slowing the growth of M. tuberculosis during infection $(\mathrm{Hu}$ et al. 2006) - being important for TB-characteristic infection latency. Hsp16.3 is also highly induced upon entry into macrophages and is crucial for both pathogen survival and virulence in the host organism (Yuan et al. 2002; Hu et al. 2006).

\section{Concluding remarks}

Bacterial sHSPs as a group are very plastic in approaching protein misfolding, aggregation, and other issues. There seems to be much specialization in their activities, though. Despite abilities to perform completely different tasks, sHSPs unite in adverse environment conditions survival, providing proteostasis protection, virulence, or other, sometimes elusive advantages. Most of these impacts and functions were found to rely on direct, stabilizing contacts with other proteins, membranes, and complexes, indicating the functional origin of SHSPs as chaperones.

Funding information The authors would like to acknowledge the support of the Polish National Science Centre (OPUS 17 2019/33/B/NZ1/00352).

Open Access This article is licensed under a Creative Commons Attribution 4.0 International License, which permits use, sharing, adaptation, distribution and reproduction in any medium or format, as long as you give appropriate credit to the original author(s) and the source, provide a link to the Creative Commons licence, and indicate if changes were made. The images or other third party material in this article are included in the article's Creative Commons licence, unless indicated otherwise in a credit line to the material. If material is not included in the article's Creative Commons licence and your intended use is not permitted by statutory regulation or exceeds the permitted use, you will need to obtain permission directly from the copyright holder. To view a copy of this licence, visit http://creativecommons.org/licenses/by/4.0/.

\section{References}

Allen SP, Polazzi JO, Gierse JK, Easton AM (1992) Two novel heat shock genes encoding proteins produced in response to heterologous protein expression in Escherichia Coli. J Bacteriol. https://doi.org/ 10.1128/jb.174.21.6938-6947.1992

Arrigo AP, Welch WJ (1987) Characterization and purification of the small 28,000-Dalton Mammalian Heat Shock Protein. J Biol Chem 262(32):15359-69

Balogi Z, Cheregi O, Giese KC, Juhász K, Vierling E, Vass I, Vígh L, Horváth I (2008) A mutant small heat shock protein with increased thylakoid association provides an elevated resistance against UV-B damage in Synechocystis 6803. J Biol Chem. https://doi.org/10. 1074/jbc.M710400200

Baron C, Biochemistry and Cell Biology-Biochimie Et Biologie Cellulaire (2006) VirB8: A Conserved Type IV Secretion System Assembly Factor and Drug Target. In: 49th Annual Conference of the Canadian-Society-of-Biochemisty-and-Molecular-and-CellularBiology Location. https://doi.org/10.1139/o06-148

Behlke J, Lutsch G, Gaestel M, Bielka H (1991) Supramolecular structure of the recombinant murine small heat shock protein Hsp25. FEBS Lett. https://doi.org/10.1016/0014-5793(91)81016-2

Bepperling A, Alte F, Kriehuber T, Braun N, Weinkauf S, Groll M, Haslbeck M, Buchner J (2012) Alternative bacterial twocomponent small heat shock protein systems. Proc Natl Acad Sci. https://doi.org/10.1073/pnas.1209565109

Berger EM, Woodward MP (1983) Small heat shock proteins in Drosophila may confer thermal tolerance. Exp Cell Res. https:// doi.org/10.1016/0014-4827(83)90225-2

Berta P, Bourg G, Hanna N, Saadeh B, Armengaud J, Patey G, O'Callaghan D (2014) The Brucella suis IbpA heat-shock chaperone is not required for virulence or for expression of the VirB type IV secretion system VirB8 protein. Lett Appl Microbiol. https://doi. org/10.1111/lam.12231

Booth RJ, Harris DP, Love JM, Watson JD (1988) Antigenic proteins of mycobacterium leprae. Complete sequence of the gene for the 18KDa Protein. J Immunol 140(2):597-601

Boyle D, Takemoto L (1994) Characterization of the $\alpha-\gamma$ and $\alpha-\beta$ complex: evidence for an in vivo functional role of $\alpha$-crystallin as a molecular chaperone. Exp Eye Res. https://doi.org/10.1006/exer.1994.1190

Capozzi V, Weidmann S, Fiocco D, Rieu A, Hols P, Guzzo J, Spano G (2011) Inactivation of a small heat shock protein affects cell morphology and membrane fluidity in Lactobacillus plantarum WCFS1. Res Microbiol. https://doi.org/10.1016/j.resmic.2011.02.010

Carra S, Alberti S, Arrigo PA, Benesch JL, Benjamin IJ, Boelens W, Bartelt-Kirbach B et al (2017) The growing world of small heat shock proteins: from structure to functions. Cell Stress Chaperones. https://doi.org/10.1007/s12192-017-0787-8

Chang Z, Primm TP, Jakana J, Lee IH, Serysheva I, Chiu W, Gilbert HF, Quiocho FA (1996) Mycobacterium tuberculosis 16-KDa antigen (Hsp16.3) functions as an oligomeric structure in vitro to suppress thermal aggregation. J Biol Chem. https://doi.org/10.1074/jbc.271.12.7218

Cocotl-Yañez M, Moreno S, Encarnación S, López-Pliego L, Castañeda M, Espín G (2014) A small heat-shock protein (Hsp20) regulated by 
RpoS is essential for cyst desiccation resistance in Azotobacter vinelandii. Microbiology (United Kingdom). https://doi.org/10. 1099/mic.0.073353-0

Cunningham AF, Spreadbury CL (1998) Mycobacterial stationary phase induced by low oxygen tension: cell wall thickening and localization of the 16-kilodalton $\alpha$-crystallin homolog. J Bacteriol. https://doi. org/10.1128/jb.180.4.801-808.1998

De Jong WWW, Leunissen JAA, Voorter CEE (1993) Evolution of the alpha-crystallin/small heat-shock protein family. Mol Biol Evol. https://doi.org/10.1017/CBO9781107415324.004

Flemming HC, Wingender J, Szewzyk U, Steinberg P, Rice SA, Kjelleberg S (2016) Biofilms: an emergent form of bacterial life. Nat Rev Microbiol. https://doi.org/10.1038/nrmicro.2016.94

Friedrich KL, Giese KC, Buan NR, Vierling E (2004) Interactions between small heat shock protein subunits and substrate in small heat shock protein-substrate complexes. J Biol Chem. https://doi.org/10. 1074/jbc.M311104200

Fu X, Chang Z (2004) Temperature-dependent subunit exchange and chaperone-like activities of Hsp16.3, a small heat shock protein from Mycobacterium tuberculosis. Biochem Biophys Res Commun. https://doi.org/10.1016/j.bbrc.2004.02.053

Fu X, Chang Z (2006) Identification of Bis-ANS Binding Sites in Mycobacterium tuberculosis Small Heat Shock Protein Hsp16.3: Evidences for a Two-Step Substrate-Binding Mechanism. Biochem Biophys Res Commun 349(1):167-171 https://doi.org/ 10.1016/j.bbrc.2006.08.036

Fu X, Zhang H, Zhang X, Yang C, Jiao W, Liu C, Yang S, Abulimiti A, Chang Z (2005) A Dual Role for the N-Terminal Region of Mycobacterium tuberculosis Hsp16.3 in Self-Oligomerization and Binding Denaturing Substrate Proteins. J Biol Chem. https://doi.org/ 10.1074/jbc.M406319200

Fu X, Shi X, Yan L, Zhang H, Chang Z (2013a) In vivo substrate diversity and preference of small heat shock protein IbpB as revealed by using a genetically incorporated photo-cross-linker. J Biol Chem. https:// doi.org/10.1074/jbc.M113.501817

Fu X, Shi X, Yin L, Liu J, Joo K, Lee J, Chang Z (2013b) Small heat shock protein $\mathrm{IbpB}$ acts as a robust chaperone in living cells by hierarchically activating its multi-type substrate-binding residues. J Biol Chem. https://doi.org/10.1074/jbc.M113.450437

Gaestel M, Burckhard G, Rainer B, Michael S, Wolf-Hagen HS, Regine K, Albrecht $\mathrm{O}$ et al (1989) Molecular cloning, sequencing and expression in Escherichia coli of the $25-\mathrm{kDa}$ growth-related protein of Ehrlich ascites tumor and its homology to mammalian stress proteins. Eur J Biochem. https://doi.org/10.1111/j.1432-1033.1989.tb14542.x

Haslbeck M, Vierling E (2015) A first line of stress defense: small heat shock proteins and their function in protein homeostasis. J Mol Biol. https://doi.org/10.1016/j.jmb.2015.02.002

Haslbeck M, Franzmann T, Weinfurtner D, Buchner J (2005) Some like it hot: the structure and function of small heat-shock proteins. Nat Struct Mol Biol. https://doi.org/10.1038/nsmb993

Hatters DM, Lindner RA, Carver JA, Howlett GJ (2001) The molecular chaperone, alpha-crystallin, inhibits amyloid formation by apolipoprotein C-II. J Biol Chem. https://doi.org/10.1074/jbc.M105285200

Hochberg GKA, Shepherd DA, Marklund EG, Santhanagoplan I, Degiacomi MT, Laganowsky A, Allison TM et al (2018) Structural principles that enable oligomeric small heat-shock protein paralogs to evolve distinct functions. Science. https://doi.org/10. 1126/science.aam7229

Horvath I, Glatz A, Varvasovszki V, Torok Z, Pali T, Balogh G, Kovacs E et al (1998) Membrane physical state controls the signaling mechanism of the heat shock response in Synechocystis PCC 6803: identification of Hsp17 as a 'fluidity gene.'. Proc Natl Acad Sci. https:// doi.org/10.1073/pnas.95.7.3513

Hu Y, Movahedzadeh F, Stoker NG, Coates ARM (2006) Deletion of the mycobacterium tuberculosis $\alpha$-crystallin-like HspX gene causes increased bacterial growth in vivo. Infect Immun. https://doi.org/ 10.1128/IAI.74.2.861-868.2006

Ingolia TD, Craig EA (1982) Drosophila gene related to the major heat shock-induced gene is transcribed at normal temperatures and not induced by heat shock. Proc Natl Acad Sci U S A. https://doi.org/10. 1073/pnas.79.2.525

Jakob U, Gaestel M, Engel K, Buchner J (1993) Small heat shock proteins are molecular chaperones. J Biol Chem 268(3):1517-20

Jiao W, Li P, Zhang J, Zhang H, Chang Z (2005) Small heat-shock proteins function in the insoluble protein complex. Biochem Biophys Res Commun. https://doi.org/10.1016/j.bbrc.2005.07.065

Key JL, Lin CY, Chen YM (1981) Heat shock proteins of higher plants. Proc Natl Acad Sci. https://doi.org/10.1073/pnas.78.6.3526

Kim KK, Kim R, Kim SH (1998a) Crystal structure of a small heat-shock protein. Nature. https://doi.org/10.1038/29106

Kim R, Kim KK, Yokota H, Kim S-h (1998b) Small heat shock protein of Methanococcus jannaschii, a hyperthermophile. Proc Natl Acad Sci U S A. https://doi.org/10.1073/pnas.95.16.9129

Kitagawa M, Miyakawa M, Matsumura Y, Tsuchido T (2002) Escherichia coli small heat shock proteins, IbpA and IbpB, protect enzymes from inactivation by heat and oxidants. Eur J Biochem. https://doi.org/10.1046/j.1432-1033.2002.02958.x

Klein G, Laskowska E, Taylor A, Lipińska B (2001) IbpA/B small heatshock protein of marine bacterium Vibrio harveyi binds to proteins aggregated in a cell during heat shock. Mar Biotechnol 3:346-354. https://doi.org/10.1007/s10126001-0009-2

Kuczyńska-Wiśnik D, Matuszewska E, Laskowska E (2010) Escherichia coli heat-shock proteins IbpA and IbpB affect biofilm formation by influencing the level of extracellular indole. Microbiology. https:// doi.org/10.1099/mic.0.032334-0

Kulig M, Ecroyd H (2012) The small heat-shock protein AB-Crystallin uses different mechanisms of chaperone action to prevent the amorphous versus fibrillar aggregation of $\alpha$-lactalbumin. Biochem J. https://doi.org/10.1042/BJ20121187

Laskowska E, Wawrzynów A, Taylor A (1996) IbpA and IbpB, the new heat-shock proteins, bind to endogenous Escherichia coli proteins aggregated Intracellularly by heat shock. Biochimie. https://doi.org/ 10.1016/0300-9084(96)82643-5

Lee BY, Hefta SA, Brennan PJ (1992) Characterization of the major membrane protein of virulent Mycobacterium tuberculosis. Infect Immun 60(5):2066-2074

Lee GJ, Pokala N, Vierling E (1995) Structure and in vitro molecular chaperone activity of cytosolic small heat shock proteins from pea. J Biol Chem. https://doi.org/10.1074/jbc.270.18.10432

Lee GJ, Roseman AM, Saibil HR, Vierling E (1997) A small heat shock protein stably binds heat-denatured model substrates and can maintain a substrate in a folding-competent state. EMBO J. https://doi. org/10.1093/emboj/16.3.659

Lee S, Prochaska DJ, Fang F, Barnum SR (1998) A 16.6-kilodalton protein in the cyanobacterium Synechocystis sp. PCC 6803 plays a role in the heat shock response. Curr Microbiol. https://doi.org/10. 1007/s002849900400

Li LK, Spector A (1974) Circular dichroism and optical rotatory dispersion of the aggregates of purified polypeptides of alpha-crystallin. Exp Eye Res. https://doi.org/10.1016/0014-4835(74)90071-2

Lini N, Rehna EAA, Shiburaj S, Maheshwari JJ, Shankernarayan NP, Dharmalingam K (2008) Functional characterization of a small heat shock protein from Mycobacterium leprae. BMC Microbiol 8:1-12. https://doi.org/10.1186/1471-2180-8-208

Loomis WF, Wheeler SA (1982) Chromatin-associated heat shock proteins of Dictyostelium. Dev Biol. https://doi.org/10.1016/00121606(82)90390-6

Maitre M, Weidmann S, Rieu A, Fenel D, Schoehn G, Ebel C, Coves J, Guzzo J (2012) The oligomer plasticity of the small heat-shock protein Lo18 from Oenococcus oeni influences its role in both 
membrane stabilization and protein protection. Biochem J. https:// doi.org/10.1042/BJ20120066

Maitre M, Weidmann S, Dubois-Brissonnet F, David V, Covés J, Guzzoa $\mathrm{J}$ (2014) Adaptation of the wine bacterium Oenococcus oeni to ethanol stress: role of the small heat shock protein Lo18 in membrane integrity. Appl Environ Microbiol 80(10):2973-2980. https:// doi.org/10.1128/AEM.04178-13

Matuszewska M, Kuczyńska-Wiśnik D, Laskowska E, Liberek K (2005) The small heat shock protein IbpA of Escherichia coli cooperates with $\mathrm{IbpB}$ in stabilization of thermally aggregated proteins in a disaggregation competent state. J Biol Chem. https://doi.org/10.1074/ jbc.M412706200

Merck KB, Groenen PJTA, Voorter CEM, De Haard-Hoekman WA, Horwitz J, Bloemendal H, De Jong WW (1993) Structural and functional similarities of bovine $\alpha$-crystallin and mouse small heat-shock protein. A Family of Chaperones. J Biol Chem. https://doi.org/10. 1093/esr/jc1027

Mörner CT (1894) Untesuchung Der Proteinsubstanzen in Den Leichtbrechenden Medien Des Auges. Hoppe Seylers Z Physiol Chem 18:61-106

Münchbach M, Nocker A, Narberhaus F (1999) Multiple small heat shock proteins in rhizobia. J Bacteriol 181(1):83-90

Nakamoto H, Honma D (2006) Interaction of a small heat shock protein with light-harvesting cyanobacterial phycocyanins under stress conditions. FEBS Lett. https://doi.org/10.1016/j. febslet.2006.04.047

Nerland AH, Mustafa AS, Sweetser D, Godal T, Young RA (1988) A protein antigen of Mycobacterium leprae is related to a family of small heat shock proteins. J Bacteriol. https://doi.org/10.1128/jb. 170.12.5919-5921.1988

Obuchowski I, Piróg A, Stolarska M, Tomiczek B, Liberek K (2019) Duplicate divergence of two bacterial small heat shock proteins reduces the demand for Hsp70 in refolding of substrates. PLoS Genet. https://doi.org/10.1371/journal.pgen.1008479

Otani M, Ueki T, Kozuka S, Segawa M, Sano K, Inouye S (2005) Characterization of a small heat shock protein, Mx Hsp16.6, of Myxococcus xanthus. J Bacteriol. https://doi.org/10.1128/JB.187. 15.5236-5241.2005

Praekelt UM, Meacock PA (1990) HSP12, a new small heat shock gene of saccharomyces Cerevisiae: analysis of structure, regulation and function. Mol Gen Genet. https://doi.org/10.1007/BF00315801

Raman B, Ramakrishna T, Rao CM (1995) Temperature dependent chaperone-like activity of alpha-crystallin. FEBS Lett. https://doi. org/10.1016/0014-5793(95)00440-K

Ratajczak E, Zietkiewicz S, Liberek K (2009) Distinct activities of Escherichia coli small heat shock proteins IbpA and IbpB promote efficient protein disaggregation. J Mol Biol. https://doi.org/10.1016/ j.jmb.2008.12.009

Richmond CS, Glasner JD, Mau R, Jin H, Blattner FR (1999) Genomewide expression profiling in Escherichia coli K-12. Nucleic Acids Res. https://doi.org/10.1093/nar/27.19.3821

Roy D, Spector A (1976) Human $\alpha$-crystallin. II. Characterization of the protein isolated from the periphery of cataractous lenses. Biochemistry. https://doi.org/10.1021/bi00650a034

Russnak RH, Don J, Peter E, Candido M (1983) Cloning and analysis of CDNA sequences coding for two 16 kllodalton heat shock proteins (Hsps) in Caenorhabditis elegans: homology with the small Hsps of Drosophila. Nucleic Acids Res. https://doi.org/10.1093/nar/11.10. 3187

Sakthivel K, Watanabe T, Nakamoto H (2009) A small heat-shock protein confers stress tolerance and stabilizes thylakoid membrane proteins in cyanobacteria under oxidative stress. Arch Microbiol 191:319 328. https://doi.org/10.1007/s00203-009-0457-z

Schlesinger MJ (1986) Heat shock proteins: the search for functions. J Cell Biol. https://doi.org/10.1083/jcb.103.2.321
Singh K, Groth-Vasselli B, Kumosinski TF, Farnsworth PN (1995) $\alpha$-Crystallin quaternary structure: molecular basis for its chaperone activity. FEBS Lett. https://doi.org/10.1016/00145793(95)00980-N

Stahl J, Wobus AM, Ihrig S, Lutsch G, Bielka H (1992) The small heat shock protein Hsp25 is accumulated in P19 embryonal carcinoma cells and embryonic stem cells of line BLC6 during differentiation. Differentiation. https://doi.org/10.1111/j.1432-0436.1992.tb00677. $\mathrm{x}$

Susek RE, Lindquist SL (1989) Hsp26 of saccharomyces Cerevisiae is related to the superfamily of small heat shock proteins but is without a demonstrable function. Mol Cell Biol. https://doi.org/10.1128/ MCB.9.11.5265

Thomas JG, Baneyx F (1998) Roles of the Escherichia coli small heat shock proteins IbpA and IbpB in thermal stress management: comparison with Clpa, Clpb, and HtpG in vivo. J Bacteriol 180(19): $5165-5172$

Tilly K, Erickson J, Sharma S, Georgopoulos C (1986) Heat shock regulatory gene RpoH MRNA level increases after heat shock in Escherichia coli. J Bacteriol. https://doi.org/10.1128/jb.168.3.11551158.1986

Tomoyasu T, Tabata A, Nagamune H (2010) Investigation of the chaperone function of the small heat shock protein AgsA. BMC Biochem 11:1-14. https://doi.org/10.1186/1471-2091-11-27

Torok Z, Goloubinoff P, Horvath I, Tsvetkova NM, Glatz A, Balogh G, Varvasovszki Vet al (2001) Synechocystis HSP17 is an amphitropic protein that stabilizes heat-stressed membranes and binds denatured proteins for subsequent chaperone-mediated refolding. Proc Natl Acad Sci. https://doi.org/10.1073/pnas.051619498

Tsai YL, Chiang YR, Wu CF, Narberhaus F, Lai EM (2012) One out of four: HspL but no other small heat shock protein of Agrobacterium tumefaciens acts as efficient virulence-promoting VirB8 chaperone. PLoS One. https://doi.org/10.1371/journal.pone.0049685

Ungelenk S, Moayed F, Ho CT, Grousl T, Scharf A, Mashaghi A, Tans S, Mayer MP, Mogk A, Bukau B (2016) Small heat shock proteins sequester misfolding proteins in near-native conformation for cellular protection and efficient refolding. Nat Commun 7:1-14. https:// doi.org/10.1038/ncomms13673

van Montfort RL, Basha E, Friedrich KL, Slingsby C, Vierling E (2001) Crystal structure and assembly of a eukaryotic small heat shock protein. Nat Struct Biol. https://doi.org/10.1038/nsb722

Veinger L, Diamant S, Buchner J, Goloubinoff P (1998) The small heatshock protein IbpB from Escherichia coli stabilizes stress-denatured proteins for subsequent refolding by a multichaperone network. J Biol Chem. https://doi.org/10.1074/jbc.273.18.11032

Verbon A, Hartskeerl RA, Schuitema A, Kolk AHJ, Young DB, Lathigra $\mathrm{R}$ (1992) The 14,000-molecular-weight antigen of Mycobacterium tuberculosis is related to the alpha-crystallin family of lowmolecular-weight heat shock proteins. J Bacteriol. https://doi.org/ 10.1128/jb.174.4.1352-1359.1992

Wang K, Spector A (1995) $\alpha$-Crystallin can act as a chaperone under conditions of oxidative stress. Investig Ophthalmol Vis Sci 36(2): $311-21$

Yang H, Huang S, Dai H, Gong Y, Zheng C, Chang Z (1999) The Mycobacterium tuberculosis small heat shock protein Hsp16.3 exposes hydrophobic surfaces at mild conditions: conformational flexibility and molecular chaperone activity. Protein Sci. https://doi.org/ 10.1110/ps.8.1.174

Yuan Y, Crane DD, Barry CE (1996) Stationary phase-associated protein expression in Mycobacterium tuberculosis: function of the mycobacterial $\alpha$-crystallin homolog. J Bacteriol. https://doi.org/10.1128/ jb.178.15.4484-4492.1996

Yuan Y, Hickey MJ, Simpson RM, Crane DD, Barry CE, Sherman DR, Zhu Y (2002) The 16-KDa-crystallin (Acr) protein of Mycobacterium tuberculosis is required for growth in macrophages. Proc Natl Acad Sci. https://doi.org/10.1073/pnas.95.16.9578 
Zhang H, Xinmiao F, Jiao W, Zhang X, Liu C, Chang Z (2005) The association of small heat shock protein Hsp16.3 with the plasma membrane of Mycobacterium tuberculosis: dissociation of oligomers is a prerequisite. Biochem Biophys Res Commun. https://doi. org/10.1016/j.bbrc.2005.03.092

Żwirowski S, Kłosowska A, Obuchowski I, Nillegoda NB, Piróg A, Ziętkiewicz S, Bukau B, Mogk A, Liberek K (2017) Hsp70 displaces small heat shock proteins from aggregates to initiate protein refolding. EMBO J. https://doi.org/10.15252/embj.201593378

Publisher's note Springer Nature remains neutral with regard to jurisdictional claims in published maps and institutional affiliations. 